\title{
RELAÇÕES INTERGOVERNAMENTAIS NA EDUCAÇÃO: FUNDOS, CONVÊNIOS, CONSÓRCIOS PÚBLICOS E ARRANJOS DE DESENVOLVIMENTO DA EDUCAÇÃO
}

\author{
Cleiton de OliveirA* \\ PEDRO GANZELI*
}

\begin{abstract}
RESUMO: Nas relações intergovernamentais e entre os entes federados e o setor privado são empregados diferentes expedientes, demonstrando a necessidade de estabelecimento de regulamentações do regime de colaboração. O artigo objetiva compreender a dinâmica que envolve a materialização de relações entre o município, foco desse trabalho, e os demais entes federados, bem como entre entidades privadas. Para tanto, analisa quatro mecanismos empregados nestas relações: fundos, convênios, consórcios públicos e arranjos de desenvolvimento da educação. O exame revelou que os mesmos são, em geral, fragmentários, conjunturais, episódicos, não concorrem para a construção do Sistema Nacional de Educação e tampouco para o estabelecimento do preceito constitucional do regime de colaboração.
\end{abstract}

Palavras-chave: Regime de colaboração. Fundos. Convênio. Consórcio público. Arranjos dedesenvolvimento da educação.

INTERGOVERNMENTAL RELATIONS IN EDUCATION:

FUNDING, PARTNERSHIPS, PUBLIC CONSORTIA AND ARRANGEMENTS FOR THE DEVELOPMENT OF EDUCATION

ABSTRACT: In the intergovernmental relations and between the federal and private sector, different expedients are used, demonstrating the need to establish regulations for collaboration frameworks. This paper aims at understanding the dynamics involving the materialization of relations between the municipalities, focus of this work, and other federal agencies as well as private entities. It analyzes four mechanisms employed in these relations: funding, partnerships, public consortia and arrangements for the development of education. Examination revealed that they are generally fragmentary, cyclical, episodic, do not contribute to the construction of the national

\footnotetext{
* Universidade Metodista de Piracicaba (Unimep). Piracicaba (SP) - Brasil.

** Faculdade de Educação da Universidade Estadual de Campinas (Unicamp). Campinas (SP) - Brasil. Contato com os autores:<cleitondeoli@gmail.com>
} 
Relações intergovernamentais na educação...

education system nor to the establishment of the constitutional principle of collaborative programs.

Key words: Collaboration framework. Funding. Partnerships. Public consortia. Arrangements for the development of education.

\title{
Relations intergouvernementales dANS L'ÉDUCATION: FONDS, ACCORDS, PARTENARIATS PUBLICS ET DISPOSITIONS DE DÉVELOPPEMENT DE L'ÉDUCATION
}

\begin{abstract}
RÉSUMÉ: Dans les relations intergouvernementales et entre les êtres fédérés et le secteur privé sont utilisées différentes formes de relations, ce qui démontre la nécessité d'établir une réglementation du régime de collaboration. L'article se met à comprendre la dynamique qui implique la matérialisation de relations entre la municipalité, cible de ce travail, et les autres êtres fédérés ainsi qu'avec des entités privées. Pour cela, on analyse quatre mécanismes employés dans ces relations : fonds, accords, partenariats publics et dispositions de développement de l'éducation. L'examen a révélé qu'ils sont, en général, fragmentaires, conjoncturels, épisodiques, ils ne collaborent pas pour la construction du système national d'éducation et ni pour l'établissement de la règle constitutionnelle du régime de collaboration.
\end{abstract}

Mots-clés: Régime de collaboration. Fonds. Accord. Partenariat public. Dispositions de développement de l'éducation.

$\mathrm{A}$ engenharia institucional do federalismo brasileiro exige, conforme disposição constitucional, o regime de colaboração entre os entes federados para garantia do direito à educação a todos os cidadãos. Por sua vez, a dinâmica federativa de composição do regime de colaboração está diretamente relacionada ao federalismo historicamente constituído no Brasil.

As diferenças regionais mostram-se como fenômeno limitante ao atendimento do espirito republicano presente na Constituição Federativa de 1988, que prevê em seu artigo 23 as competências comuns da União, dos estados, do Distrito Federal e dos municípios, para proporcionar os meios de acesso à cultura, à educação e à ciência, garantindo assim, por ação solidária dos entes federados, o bem-estar de todos os brasileiros.

Após 15 anos de promulgação da Carta Magna, o regime de colaboração não foi regulamentado por lei complementar. Em 2006, por força da Emenda Constitucional n. 53, houve alteração na redação do parágrafo único do artigo 23, empregando-se o plural para a regulamentação do regime de colaboração, ficando assim registrado: “Leis Complementares fixarão normas para a cooperação entre a União e os estados, o Distrito Federal e os municípios, tendo em vista o equilíbrio do desenvolvimento e do bem-estar em âmbito nacional". Esta alteração considerou a complexidade da regulamentação do dispositivo em uma única lei e possibilitou eventuais ajustes ao longo do tempo. 
Cabe destacar que estamos diante de um processo de institucionalização de relações entre os entes federados, com a definição de atribuições, competências, formas de financiamento e criação de estruturas de gestão intergovernamentais, que constituem a organização do Estado brasileiro, ou seja, constituintes de políticas de Estado para a educação.

A legislação mostra-se de fundamental importância na constituição do regime de colaboração. Porém, é preciso compreender que são os governos (nacional, regional e local) que produzem a materialização do regime de colaboração, com acertos e desacertos conjunturais e históricos. Nesse sentido, estamos compreendendo essas relações intergovernamentais como políticas de Estado ou políticas de governo.

O objetivo desse artigo é analisar quatro mecanismos utilizados nas relações intergovernamentais, bem como entre os governos e o setor privado: fundos, convênios, consórcios públicos e arranjos de desenvolvimento da educação, buscando compreender a dinâmica que envolve a materialização do regime de colaboração na área da educação.

Iniciamos nossa análise com a contextualização histórica do regime de colaboração na área da educação, indicando o marco legal e sua influência nas relações intergovernamentais, tendo como foco a esfera municipal. Em seguida, abordaremos o financiamento, com destaque para a política de fundos, na constituição do regime de colaboração. Finalizamos o artigo analisando cada instrumento que promove a relação intergovernamental: fundos, convênios, consórcios públicos e arranjos de desenvolvimento da educação.

\section{Regime de colaboração}

A Constituição Federal de 1988 elevou o município à condição de ente federado, definindo atribuições e competências privativas e comuns com os demais entes que compõem a organização político administrativa do país - estados, Distrito Federal e União. Constitui-se assim um federalismo tripartite que deve atuar em regime de colaboração. A regulamentação do regime de colaboração por leis complementares, no entanto, ainda não foi formalizada, registrando pelo menos cinco tentativas no Congresso Nacional (ARAÚJO, 2012), sem levar a cabo a empreitada.

As experiências de federalismo não seguem um modelo único, sendo determinadas por razões históricas, econômicas e culturais, tendo em comum a característica de não serem unitárias, respeitando uma autonomia, maior ou menor conforme o caso, entre suas instâncias. Cury (2010, p. 153), ao tratar o assunto, apresenta três tipos gerais de federalismo pelos quais passou o Brasil $^{1}$ - centrípeto, centrífugo e de cooperação -, situando no último a proposta constitucional brasileira de 1934 
Relações intergovernamentais na educação...

e de 1946, constituindo "o registro forte de nossa atual Constituição". Pretende-se com o regime de colaboração superar a competição entre entes federados. No caso brasileiro, ainda esta se faz presente, por exemplo, pela guerra fiscal - ICMS, ISS, isenções fiscais, entre outros - e pela questão dos royalties do petróleo.

Em relação à educação, que interessa mais de perto a este trabalho, a Constituição Federal estabelece em seu artigo 211 que "A União, os estados, o Distrito Federal organizarão em regime de colaboração seus sistemas de ensino", e acrescenta no $\S 4^{\circ}$ que os entes federados "definirão formas de colaboração de modo a assegurar a universalização do ensino obrigatório". A Lei n. 9.394/96, Lei de Diretrizes e Bases da Educação Nacional (LDBEN), repete o preceito em seu artigo 8o, registrando, em seu $\S 1^{\circ}$ que “Caberá à União a coordenação da política nacional de educação, articulando os diferentes níveis e sistemas e exercendo função normativa, redistributiva e supletiva em relação às demais instâncias educacionais". As incumbências da União estão registradas no artigo 9º da LDBEN; dos estados, no artigo 10, e dos municípios no artigo 11; ao Distrito Federal cabem as atribuições referentes aos estados e municípios, conforme o parágrafo único do artigo 10.

O regime de colaboração entre os estados e os municípios está fixado pela LDBEN em relação ao nível de atuação, sendo responsáveis pela manutenção e desenvolvimento do ensino fundamental, podendo os municípios, para tanto, criar sistema próprio de ensino (artigo 11, I), ou optar "por se integrar ao sistema estadual de ensino ou compor com ele um sistema único de educação básica" (artigo 11, parágrafo único). O âmbito de atuação dos sistemas federal está definido Art.16, dos estados no artigo 17 e dos municípios no artigo 18. Outros artigos desta Lei registram atribuições e competências dos entes federados. ${ }^{2}$

A Constituição Federal de 1988, ao ampliar as competências e atribuições dos entes federados subnacionais, reconhece o trabalho que historicamente os mesmos desenvolveram no país. De fato, a interpretação que prevaleceu do Ato Adicional de 1834 levou as províncias a assumirem o ensino das primeiras letras (SUCUPIRA, 1996), essas foram desincumbindo-se da determinação com o auxílio das municipalidades (OLIVEIRA, 1999), permanecendo a situação na primeira república (NAGLE, 1974). A Lei n. 4.024/1961 criou os sistemas estaduais e distrital de educação, bem como os conselhos estaduais de educação. A Lei n. 5.692/71 avançou ao prever a possibilidade da existência de conselhos municipais de educação nos municípios. A legislação atual manteve os colegiados em todos os níveis e possibilitou, conforme já afirmado, a existência de sistemas municipais de educação.

Em relação ao financiamento do ensino, também se verifica o envolvimento das diferentes instâncias. Assim, desde a Constituição Federal de 1934, exceto nas de 1937 e de 1967, períodos autoritários, houve vinculação orçamentária para a educação. A Emenda Constitucional n.1 de 1969 registrou a exigência apenas para o nível 
municipal; a Emenda Calmon de 1983 retomou a exigência para todas as instâncias, sendo regulamentada em 1985, devendo ser observada a partir do exercício de 1986.

O movimento descentralizador do ensino, consagrado pela Constituição Federal de 1988, não tem uma causa única: comporta as explicações históricas apresentadas sobre o envolvimento das esferas administrativas, acresce que procurou responder ao movimento político pela democratização que, entre outras medidas, propunha a descentralização como resposta à centralização vivenciada no período autoritário militar e, também, ao movimento descentralizador proposto por agências internacionais experimentado em países da região.

O regime de colaboração pressupõe o desenvolvimento de trabalho conjunto entre entes federados, podendo se dar na dimensão horizontal e vertical, conforme tradicionalmente se registra. No primeiro caso, a articulação se dá entre entes da mesma esfera administrativa; no segundo, a mesma ocorre entre entes de outras esferas. A expressão articulação vertical, por sua vez, vem sendo criticada porque pressupõe a existência de níveis diferentes entre os entes federados. Sobre a questão o Parecer CNE/CEB n. 9/2011, afirma que "as relações interfederativas não se dão mais por processos hierárquicos ${ }^{3}$ e sim por meio do respeito aos campos próprios das competências assinaladas, mediadas e articuladas pelo principio da colaboração recíproca e dialogal". Por outro lado, há autores que reconhecem a existência de diferenciações entre os entes federados no estabelecimento de atividades conjuntas, como ocorre no Plano de Ações Articulas (PAR), envolvendo a esfera federal e as demais esferas (AZEVEDO, SANTOS, 2012; LUCE; FARENZENA, 2007).

As articulações interinstitucionais dos municípios se dão com outros municípios, com os estados e com a União; registram-se também parcerias com o setor privado e com a comunidade. Conforme dados do Perfil dos Municípios Brasileiros (IBGE, 2011), dos 5.565 municípios brasileiros, 4.497 registraram articulação interinstitucional, 4.175 por meio de consórcios, 3.295 por meio de consórcios públicos com diferentes entes federados, 1.920 por meio de convênio de parceria com o setor privado e 1.203 com o apoio do setor privado ou com a comunidade. Essas relações são formalizadas pela constituição de fundos, pelo estabelecimento de convênios, contratos, consórcios e arranjos diversos.

As diferentes modalidades de articulações são buscadas pelos entes federados no intuito de sanar ou minorar os problemas que enfrentam. Considerando a variedade de parceiros e de instrumentos de formalização das articulações, podemos afirmar que muitas destas iniciativas correspondem a políticas de governo e não políticas de Estado. Aquelas correspondem às iniciativas do Executivo, têm a marca da gestão, são pontuais e, em geral, envolvem pouca discussão e têm chances de descontinuidade. Já as políticas de Estado são resultantes de processos que envolvem interlocutores diversos, são portadoras de propostas mais amplas e que vão além 
Relações intergovernamentais na educação...

do período da gestão, "resultando em mudanças de outras normas ou disposições pré-existentes, com incidência em setores mais amplos da sociedade" (OLIVEIRA, 2011, p. 329).

A seguir, vamos nos deter na análise das diferentes possibilidades mais usuais de parcerias vivenciadas pelos municípios: fundos para a educação, convênios, consórcios públicos e arranjos de desenvolvimento da educação.

\section{Fundos para a educação}

A falta de recursos para a educação tem sido uma constante em nossa história. Das dificuldades enfrentadas pela distância do poder central em relação à educação das primeiras letras, passou-se à vinculação obrigatória constitucional e, posteriormente, à criação do Fundo Nacional do Ensino Primário em 1942. A LDB de 1961 estabeleceu que, "Com nove décimos dos recursos federais destinados à educação, serão constituídos em parcelas iguais, o Fundo Nacional do Ensino Primário, o Fundo Nacional do Ensino Médio e o Fundo Nacional do Ensino Superior", conforme o $\S 1^{\circ}$ do artigo 92. A igualdade proposta ia de encontro à realidade, uma vez que o ensino primário era o único obrigatório e gratuito e atendendo um número maior de alunos.

A ideia de um fundo para o ensino primário, envolvendo as três esferas de governo, foi aventada por Anísio Teixeira, inicialmente em 1957, propondo a municipalização do ensino e o financiamento a partir das necessidades encontradas, estabelecendo percentuaisde investimento para salários, material didático, prédios e administração. $\mathrm{O}$ autor voltou à questão em outras ocasiões, aperfeiçoando sua proposta inicial, mantendo porém o envolvimento das instâncias e considerando as carências locais como ponto de partida (ROSSINHOLI, 2010).

A ideia de fundo foi retomada, em bases diferentes, pela Emenda Constitucional n. 14/96 com a criação do Fundo de Manutenção e Desenvolvimento do Ensino Fundamental e de Valorização do Magistério (Fundef). Este fundo contábil, de âmbito estadual e com a duração de dez anos, foi constituído por recursos oriundos dos municípios e dos estados, sendo redistribuído pelo número de alunos do ensino fundamental das escolas públicas mantidas por estas esferas de governo. $O$ fundo tornou-se, por conseguinte, forte indutor à municipalização e provocou a igualdade do valor/aluno no âmbito estadual, independente dos recursos locais. À União coube completar os recursos dos fundos estaduais em que o valor/aluno não atingisse o mínimo estabelecido nacionalmente. Foi previsto percentual do fundo para pagamento do magistério e a existência de Conselho de Acompanhamento e Controle Social dos recursos do Fundo nas três esferas de governo. $\mathrm{O}$ fundo restringiu-se ao 
ensino fundamental, deixando a educação infantil e o ensino médio sem os recursos do mesmo.

Vencido o período de vigência do Fundef foi criado, em bases semelhantes, o Fundo de Manutenção e Desenvolvimento do Ensino Básico e de Valorização dos Profissionais da Educação (Fundeb), com a vigência de 14 anos, cobrindo todo o ensino básico, tendo ampliada a fonte de seus recursos e diversificada a redistribuição dos mesmos, considerando as etapas, modalidades e tipos de estabelecimento de ensino. Inovou ao criar a Comissão Intergovernamental de Financiamento para a Educação Básica de Qualidade, composta por uma representante do MEC, cinco representantes da União Nacional dos Dirigentes Municipais de Educação (Undime) e cinco do Conselho Nacional de Secretários Estaduais de Educação (Consed), com a finalidade de determinar as ponderações referentes aos fatores de redistribuição dos recursos. Os Conselhos de Acompanhamento e Controle tiveram suas composições ampliadas, assim como as salvaguardas para seus membros e a especificação dos que não podem participar do mesmo, tendo em vista a proximidade com o Executivo nas três esferas de governo. $\mathrm{O}$ valor mínimo por aluno continua sendo estabelecido anualmente e a União definiu sua participação em no mínimo 10\% do valor do fundo.

A ideia de fundo para a manutenção e desenvolvimento do ensino foi muito discutida durante a tramitação da Emenda Constitucional que deu origem ao Fundeb, não faltando propostas, com diferentes combinações, entre etapas de ensino, inclusive para o ensino superior (ROSSINHOLI, 2010). Esta foi igualmente retomada durante a Conferência Nacional de Educação (CONAE) em 2010. Considerando a vigência do Fundef e do Fundeb, o país viverá a experiência de fundos para a educação durante 24 anos - tempo suficiente para mostrar suas vantagens e limitações. Os dois fundos igualam o valor/aluno no âmbito do estado, porém em âmbito nacional continua existindo a diferenciação, garantindo-se o valor mínimo para todos, porém não um valor único. A participação dos estados e municípios nestes fundos se dá por imposição constitucional, não sendo, portanto, voluntária.

\section{Convênios}

Convênio, acordo ou ajuste corresponde a pacto estabelecido entre órgãos públicos ou entre órgãos públicos e entidades privadas sem fins lucrativos para a execução de programas governamentais, "envolvendo a realização de projeto, atividade, serviço, aquisição de bens ou evento de interesse recíproco, em regime de mútua cooperação" (Decreto Federal n. 6.170, de 25 de julho de 2007). Os convêniospodem ser realizados entre entes federados e setor privado. Este é constituído por: Organizações da Sociedade Civil de Interesse Público (Oscip), por entidades comunitárias, confessionais e filantrópicas; por instituições privadas em sentido estrito. 
Os convênios são instrumentos ágeis para o estabelecimento e desenvolvimento de programas governamentais, são empregados geralmente em políticas de governo e não de Estado, dado o processo de elaboração, de tramitação dos mesmos e o grau de abrangência temporal. Os convênios não são obrigatórios, devendo haver concordância de ambas as partes para seu estabelecimento, repactuação quando do vencimento e rescisão por vontade de quaisquer das partes conveniadas. Observa-se que convênios, principalmente entre estados e municípios, não raro são lançados pelos primeiros com vantagens iniciais, atuando como efeito demonstrativo para a obtenção de apoio dos segundos. Não é incomum que a obtenção dos pleitos em determinada secretaria estadual esteja ligada à assinatura de convênio em outra secretaria. A questão partidária pode também facilitar ou dificultar a assinatura de convênios públicos.

Dados do Perfil dos Municípios Brasileiros (IBGE, 2011) indicam que 712 municípios declararam ter estabelecido convênio com o setor privado na área da educação; 440 municípios declararam ter recebido apoio do setor privado ou da comunidade.

Os convênios estabelecidos com particulares, na área educacional, têm ocorrido principalmente na compra de vagas e nas assessorias. Os municípios têm encontrado dificuldades em atender às demandas por vagas na educação infantil, principalmente no que se refere às creches, alegando falta de recursos ou os limites estabelecidos pela lei de responsabilidade fiscal. A procura tem sido muito grande, considerando os déficits acumulados, a importância que os pais passaram a dar para esta etapa, bem como a necessidade de trabalho das mães. $\mathrm{O}$ direito à vaga nesta etapa, não raro, é conseguido pela via do Ministério Público. Daí o expediente utilizado por muitos municípios de conveniar-se com particulares para o atendimento da demanda ou, ainda, o município constrói o prédio e o cede à instituição particular, que se encarrega do seu funcionamento. Esta é uma das formas do setor privado assumir atribuições públicas, pautando ações na área. Não é sem outro motivo que entre as propostas da Conae (2014) está a de congelamento do número de vagas em creches conveniadas.

Os convênios com empresas particulares ou organizações não governamentais de assessoria têm, entre as explicações para seu crescimento e protagonismo no cenário educacional, a multiplicação de sistemas próprios municipais de ensino sem as condições de recursos humanos que se responsabilizem pela administração do sistema - organização do órgão municipal de educação, plano municipal de educação, plano de carreira para os profissionais do magistério, entre outros - e pela parte pedagógica - currículo escolar, formação continuada dos profissionais da educação, entre outros. Resulta daí o "ensino apostilado" e, consequentemente, a ingerência do setor privado no público. Assim, "o setor privado amplia seu mercado ao incidir 
sobre o espaço público na mesma medida em que o setor público transfere parcela de suas responsabilidades para com a educação à iniciativa privada" (ADRIÃO et al., 2009, p. 801). Outra consequência da adoção do "ensino apostilado" reside na desqualificação docente, ou seja, o professor deixa de ser o formulador de sua atividade profissional, tornando-se mero executor de atividades pensadas por outro.

\section{Consórcios públicos}

Os consórcios constituem formas de associativismo entre entes federados, com objetivos explícitos e comuns, pertencendo os integrantes a uma mesma territorialidade. Esta modalidade de associativismo tem sido proposta como uma maneira de racionalizar ações que procuram resolver problemas comuns, os quais têm dimensões e complexidades que vão além dos recursos humanos e econômicos, bem como extrapolam os limites territoriais de um único município.

A Lei n. 11.107, de 6 de abril de 2005, dispôs sobre as normas gerais sobre a participação de entes federados em consórcios públicos. De acordo com o artigo 6º há duas possibilidades dos consórcios em relação à personalidade jurídica: de direito público ou de direito privado. Na primeira, integra a administração indireta dos entes federados que estão consorciados; na segunda, deverá observar o atendimento dos requisitos da legislação civil. A União, por força do $\S 2^{\circ}$, do artigo $1^{\circ}$, "somente participará de consórcios públicos em que também façam parte todos os estados em cujos territórios estejam situados os municípios consorciados".

Os consórcios municipais tiveram desenvolvimento "principalmente nas décadas de 1980 e 1990, como parte da estratégia de descentralização de algumas políticas públicas. Um exemplo ocorreu no estado de São Paulo, com o governador Montoro (1983-1986), que incentivou a criação de consórcios" (CRUZ; ARAÚJO; BATISTA, 2011, p. 112). São citados na literatura como exemplos de sucesso: Consórcio Intermunicipal das Bacias dos Rios Piracicaba, Capivari e Jundiaí - constituído como associação civil de direito privado sem fins lucrativos, criado em 1989, composto por 43 municípios e 29 empresas, tendo como objetivo a recuperação e manutenção das referidas bacias hidrográficas - e Consórcio Intermunicipal do Grande ABC, consórcio público de natureza autárquica, criado em 1990, composto por sete municípios, com objetivo multissetorial.

Em 2011, conforme dados do Perfil dos Municípios Brasileiros (IBGE, 2011), dos 5.565 municípios brasileiros, 2.903 declararam participar de consórcio público intermunicipal. As áreas em que se consorciaram foram as seguintes: saúde (2.288municípios); meio ambiente (704); turismo (456); saneamento básico (426); desenvolvimento urbano (402); educação (280); cultura (248); habitação (241); assistência e desenvolvimento social (232); transporte (211); emprego e trabalho (143). 
Pela distribuição, observa-se que a área mais consorciada é a da saúde, sendo a de educação pouco explorada. A primeira é desenvolvida pelo Sistema Único de Saúde, o qual envolve os entes federados, apresenta demandas além da capacidade atual de atendimento e os casos complexos exigem tratamento que, em geral, vão além da capacidade de cada município isoladamente considerado. A existência de número relativamente baixo de consórcios na área educacional explica-se, entre outros motivos, pelo fato dos municípios serem responsáveis pela manutenção e desenvolvimento da educação infantil e, juntamente com o sistema estadual, pelo ensino fundamental, preocupando-se primordialmente pela cobertura. As experiências de consórcio na área da educação concentram-se principalmente em atividades de formação inicial e continuada dos profissionais da educação, bem como na expansão do ensino superior.

\section{Arranjos de desenvolvimento da educação}

O Conselho Nacional de Educação aprovou o Parecer CNE/CEB n. 9, em 30 de agosto de 2011, referente à "análise de proposta de fortalecimento e implementação do regime de colaboração mediante arranjos de desenvolvimento da educação", centrando-se na análise da situação entre municípios, "numa espécie de colaboração horizontal". Para tanto, recomenda o trabalho em rede entre municípios geograficamente próximos e que possuam "características sociais e econômicas semelhantes", com o objetivo de "trocar experiências e solucionar conjuntamente dificuldades na área de educação, trabalhando de forma articulada com os estados e União, promovendo e fortalecendo a cultura do planejamento integrado e colaborativo na visão territorial e geopolítica". Para o desenvolvimento de um trabalho integrado, propõe a ação intermunicipal, necessariamente com a participação do estado e da União, incluindo ou não instituições privadas e não governamentais, "sem que haja para isso transferência de recursos públicos para tais instituições e organismos privados".

O Parecer reconhece a necessidade de trabalho conjunto, considerando as dificuldades que os municípios isoladamente podem encontrar, bem como a fragmentação que não concorre para a construção do Sistema Nacional de Educação. Ao propor o trabalho conjunto, emprega a expressão "arranjos" no plural por reconhecer a não existência de um modelo único e engessador que possa atender às necessidades regionais. Assim, cita inicialmente os consórcios públicos como uma das possibilidades, apresentando exemplos de iniciativas bem-sucedidas desenvolvidas sob esta modalidade; apresenta também arranjos elaborados em bases etnográficas, como a possibilidade encontrada na educação indígena.

O documento propõe que os arranjos na área educacional sejam planejados a partir dos indicadores do PAR, programa integrante do Plano de Desenvolvimento 
da Educação (PDE), lançado pelo MEC em 2007. São citados quatro exemplos de arranjos planejados, constituídos em 2009, sob esta orientação: Arranjo Corredor Carajás, com apoio do MEC, da Comunidade Educativa (Cedac), da Fundação Vale e do movimento Todos pela Educação, compreendendo 16 municípios; Arranjo do Recôncavo Baiano, com o apoio do movimento Todos pela Educação e Instituto Votorantim, planejado para 12 municípios; Arranjo do Agreste Meridional de Pernambuco, com apoio do movimento Todos pela Educação e do Sesi-PE e da Confederação Nacional da Indústria, congregando 23 municípios; Arranjo Noroeste de São Paulo, com apoio do movimento Todos pela Educação, associando 18 municípios.

O movimento Todos pela Educação, apoiador dos quatro arranjos citados como experiências ilustrativas das vantagens da proposta, é constituído por pessoas físicas com o apoio de importantes entidades e empresas industriais e de serviços. A influência da entidade é grande, considerando que seus membros e simpatizantes ocupam cargos em governos estaduais e federal, além de acesso à mídia. A influência teria nascido antes, desde a legislação de 2007, culminando com a proposta contida no Parecer (ARAÚJO, 2012).

O apadrinhamento de escolas por parte de empresas e de fundações é uma realidade que se fez presente principalmente a partir dos anos de 1990. A crítica que, em geral, se faz a este tipo de parceria é que na mesma pretende-se impor um modelo de administração empresarial à escola. Já há três décadas, pelo menos, procura-se evidenciar que a administração de empresa não atende às especificidades de que é portadora a educação e, por extensão, a escola. Daí, por exemplo, as infrutíferas tentativas de aplicar inovações administrativas, de base empresarial e comprometida com o mercado na educação, haja vista a empolgação havida com a qualidade total, os investimentos para aplicá-la em escolas e o silêncio advindo do fracasso ao tentar padronizar as relações ensino-aprendizagem.

O arranjo proposto no Parecer vai além da escola ou do município, pretendendo abarcar municípios de uma mesma área geográfica e com características comuns. Embora esteja enfatizado que não haverá pagamento para as entidades que apoiarem a proposta, é de se prever que os problemas enfrentados na experiência de escolas adotadas se repitam ampliadamente, uma vez que as propostas dos entes federados poderão ser eclipsadas pelas ideias e inovações que o novo parceiro tentará, em nome do progresso, impor aos associados.

A proposta despolitiza a discussão do regime de colaboração ao reduzi-la a mera questão administrativa e técnica, valendo-se da ausência de uma ação mais incisiva da União para avançar a questão (ARAÚJO, 2012). O adiamento do enfrentamento da questão leva a soluções parciais e fragmentárias, não colaborando para o diálogo que possibilite avançar politicamente, respeitando a especificidade da educação e os entes federados. 


\section{Outras experiências associativas}

Além das formas associativas expostas, há ainda algumas outras praticadas em função da realidade socioeconômica, dentre estes destacamos: ajustes no próprio município, entre a esfera local e a estadual, em relação às atividades desenvolvidas pela primeira, referente ao apoio, manutenção de equipamentos e cessão de pessoal aos equipamentos da segunda, principalmente na área da educação; ajustes entre municípios vizinhos, principalmente entre conurbados, em diferentes áreas, principalmente em relação ao saneamento básico, transportes e educação; planejamento e desenvolvimento de atividades em diferentes áreas nas regiões metropolitanas.

O processo de urbanização no Brasil foi muito intenso nas últimas décadas e registra $84,4 \%$ da população morando em cidades em 2010. Este crescimento se explica, entre outras possíveis causas, pelas alterações no modo de produção agrícola, pelo êxodo rural, pela industrialização e crescimento do setor terciário, provocando um adensamento populacional que, em diversos casos, extrapolam as divisas municipais, constituindo regiões metropolitanas, "cuja dinâmica não está circunscrita a uma única esfera de decisão" (FIRKOWSKI, 2013, p. 41). Assim, torna-se necessário o planejamento integrado, tendo em vista, entre outras finalidades, a prestação de serviços básicos à população. A criação de regiões metropolitanas, de acordo com a Constituição Federal de 1988, constitui atribuição estadual. Atualmente, há no Brasil 54 regiões metropolitanas e três Regiões Integradas de Desenvolvimento (Ride), compreendendo municípios de diferentes estados, sendo sua criação incumbência federal. ${ }^{4}$ As regiões metropolitanas têm organizações diferentes. A de Campinas (SP), por exemplo, é constituída porum Conselho de Desenvolvimento, composto pelos seus 19 prefeitos municipais, assessorado por 13 Câmaras Temáticas, entre as quais a de Educação, onde os dirigentes municipais e representantes do sistema estadual de ensino têm assento, revelando-se como um espaço importante para troca de experiências e tomada de decisões conjuntas (OLIVEIRA et al., 2006).

Outras formas de associativismo podem ainda ser citadas, embora não sejam objeto de análise, por fugirem ao objetivo do estudo: o caso das cidades "gêmeas", municípios conurbados pertencentes a países diferentes (no caso brasileiro, são mais encontradas em relação aos países do Cone Sul); o Programa Cidades Educadoras, desenvolvido em rede mundial, contando com a participação de 15 municípios brasileiros de diferentes estados. A Undime, associação de âmbito nacional que atua desde 1986, constitui um importante espaço de interlocução e de representação dos interesses municipais na área educacional em relação ao MEC e seus órgãos e ao Legislativo, tanto em âmbito estadual quanto nacional. 


\section{Considerações finais}

O regime de colaboração como política de Estado compreende a institucionalização de atribuições, competências, formas de financiamento, criação de estruturas intergovernamentais de gestão educacional e adoção de mecanismos que garantam a integração dos entes federados, respeitando suas autonomias. Deve orientar-se no sentido de criação do Sistema Nacional de Educação, tendo como parâmetro o Plano Nacional de Educação que supere as desigualdades regionais e garanta a promoção do direito à educação. Para tanto, torna-se necessário e fundamental a regulamentação do regime de colaboração de forma a se orientar para o estabelecimento de políticas de estado.

A Constituição Federal proclama o federalismo cooperativo nas relações entre os entes federados, fazendo reiteradas referências ao regime de colaboração e empregando as seguintes expressões: cooperação, acordo, ajuste, convênio e contrato. Nesse trabalho, sob esta perspectiva, analisamos os fundos, convênios, consórcios públicos e arranjos de desenvolvimento da educação.

Os fundos incorporam-se à estrutura organizacional do Estado, integrando entes municipais e estadual, conforme o caso, com o federal, na composição, distribuição e controle dos recursos; por outro lado, a participação dos entes subnacionais é imposta e os efeitos da distribuição igualitária de recursos limitam-se ao âmbito estadual.

Os convênios favorecem a agilidade na relação intergovernamental, são empregados para atender a demandas pontuais, com prazos estabelecidos, em geral limitando-se a mandatos do Poder Executivo, configurando-se a pactos conjunturais.

Os consórcios públicos revelam-se eficazes no enfrentamento de problemas que ultrapassam a capacidade de atuação de um único ente federado. Sua institucionalização jurídica pode concorrer para uma ação duradoura. Por estar circunscrito territorialmente e em relação ao atendimento regionalizado, não concorre para o estabelecimento de um Sistema Nacional de Educação.

Os Arranjos de Desenvolvimento da Educação privilegiam a integração de municípios agrupados em um mesmo território. A influência da concepção gerencial que perpassa a proposta acaba por despolitizar a discussão sobre o regime de colaboração e, ao mesmo tempo, reforça a ingerência de interesses do setor privado localizados regionalmente na educação pública.

A análise revelou que no relacionamento intergovernamental são empregados mecanismos que nem sempre concorrem para o preceito constitucional do regime de colaboração. Apresentam-se como mecanismos integradores entre os signatários, mas são, entretanto, fragmentários, conjunturais e não concorrem para a construção 
Relações intergovernamentais na educação...

do Sistema Nacional de Educação, comprometendo a garantia da efetivação da educação como direito.

\section{Notas}

1. "O federalismo centrípeto se inclina ao fortalecimento do poder da União [...] em que predominam as relações de subordinação dentro do Estado federal"; o "federalismo centrífugo remete ao fortalecimento do poder do Estado-membro sobre o da União". O autor apresenta, como exemplo do primeiro tipo, o “Brasil entre os anos 1930-1934, 1937-1945 e 1964-1988", já o segundo tipo é ilustrado pela experiência brasileira na República Velha (CURY, 2010, p. 153).

2. A LDBEN registra, ainda, em relação à "formação inicial, a continuada e a capacitação dos profissionais do magistério", que se trata de atividade a ser desenvolvida em conjuntos pelos entes federados (art. 62). O custo/aluno será definido pela União em colaboração com os demais entes federados (art. 74). Os entes federados subnacionais e supletivamente têm atribuições também elencadas no artigo 87, $\S 3^{\circ}$. Dois dispositivos reforçam a função reguladora da União: a obrigação dos entes federados de "integrar todos os estabelecimentos do ensino fundamental do seu território ao sistema nacional de avaliação do rendimento escolar" (art. 74, ADCT) e a inclusão feita ao artigo 87,§3º ADCT, pela Lei n. 12 .796/ 2013, segundo a qual "A União prestará assistência técnica aos estados, ao Distrito Federal e aos municípios na elaboração de concursos públicos para provimento de cargos dos profissionais da educação".

3. Embora o trecho citado advogue a não existência de hierarquização no processo de relação entre os entes federados, as expressões "horizontal" e "vertical" são usualmente empregadas inclusive no próprio Parecer CNE/CEB n. 9/2011.

4. O Brasil contava com nove regiões metropolitanas até 1974. A partir da atual Constituição Federal o número chegou a 54, variando os critérios para a determinação das mesmas. O número de habitantes, por exemplo, é extremamente diferente da Região Metropolitana da Grande São Paulo, com 19.683.975 habitantes, até a Região Metropolitana do Sul do Estado de Roraima (Caroebe) com 21.633 habitantes (FIRKOWSKI, 2013). São três as regiões integradas de desenvolvimento: Juazeiro - Petrolina, composta por oito municípios, sendo quatro da Bahia e quatro de Pernambuco; Grande Teresina - Timon, compreendendo 14 municípios, sendo um do Maranhão e os demais do Piauí; Entorno do Distrito Federal, constituída por 22 municípios, sendo três de Minas Gerais e os demais de Goiás.

\section{Referências}

ADRIÃO, T. et al. Uma modalidade peculiar de privatização da educação pública: a aquisição de "sistemas de ensino" por municípios paulistas. Educação \& Sociedade, Campinas, v.30, n. 108, p. 799-818, out. 2009.

ARAÚJO, G.C. Federalismo cooperativo e arranjos de desenvolvimento da educação: o atalho silencioso do empresariado para a definição e regulamentação do regime de colaboração. Revista Brasileira de Política e Administração da Educação, Recife, v. 28, n.2, p. 515-531, 2012.

AZEVEDO, J.M.L.; SANTOS, A.L.F. Influências do poder central no planejamento da educação dos municípios da região metropolitana do Recife. Educação \& Sociedade, Campinas, v. 33, n. 119, p. 551-573, abr.jun. 2012. 
BRASIL. Constituição (1988). Constituição da República Federativa do Brasil. Brasília, DF: Senado Federal, 1988.

BRASIL. Emenda Constitucional n. 14, de 12 de setembro de 1996. Modifica os arts. 34, 208, 211 e 212 da Constituição Federal e dá nova redação ao art. 60 do Ato das Disposições Constitucionais Transitórias. Diário Oficial da União, Brasília, DF, Seção I, p. 18-109, 13 set. 1996a. Disponível em: <http://www.planalto.gov.br/ccivil_03/ constituicao/Emendas/Emc/emc14.htm> Acesso em: 20 maio 2013.

BRASIL. Emenda Constitucional n. 53, de 19 de dezembro de 2006. Dá nova redação aos arts. \&º , 23, 30, 206, 208211 e 212 da Constituição Federal e dá nova redação ao art. 60 do Ato das Disposições Constitucionais transitórias. Disponível em: <http:// www.planalto.gov.br/ccivil_03/constituicao/Emendas/Emc/emc53.htm>. Acesso em: 16 maio 2013.

BRASIL. Lei n. 4.024, de 20 de dezembro de 1961. Fixa as diretrizes e bases da educação nacional. Disponível em: <http://www.planalto.gov.br/ccivil_03/leis/14024.htm>. Acesso em: 7 maio 2013.

BRASIL. Lei n. 5.692, de 11 de agosto de 1971. Fixa as Diretrizes e Bases para o ensino de $1^{\circ}$ e $2^{\circ}$ graus, e dá outras providências. Disponível em <http://www.planalto.gov. br/ccivil_03/leis/15692.htm>. Acesso em: 16 maio 2013.

BRASIL. Lei n. 9394, de 20 de dezembro de 1996. Estabelece as diretrizes e bases da educação nacional. Disponível em: <http://www.planalto.gov.br/ccivil_03/leis/ 19394.htm>. Acesso em: 22 abr. 2013.

BRASIL. Lei n. 9.424, de 24 de dezembro de 1996. Dispõe sobre o Fundo de Manutenção e Desenvolvimento do Ensino Fundamental e de Valorização do Magistério na forma prevista no art. 60 do Ato das Disposições Constitucionais Transitórias e dá outras providências. Disponível em: <http://www.planalto.gov.br/ccivil_03/ leis/19424.htm>. Acesso em: 7 maio 2013.

BRASIL. Lei n. 11.107, de 6 de abril de 2005. Dispõe sobre normas gerais de contratação de consórcios públicos e dá outras providências. Disponível em: <http://www. planalto.gov.br/ccivil_03/_ato2004-2006/2005/lei/111107.htm>. Acesso em: 12 mar. 2013.

BRASIL. Lei n. 11 494, de 20 de junho de 2007. Regulamenta O Fundo de Manutenção e Desenvolvimento da Educação Básica e de Valorização dos Profissionais da Educação - Fundeb, de que trata o art. 60 do Ato das Disposições Constitucionais Transitórias. Disponível em: <http://www.planalto.gov.br/ccivil_03/_ato2007-2010/2007/ Lei/L11494.htm>. Acesso em: 7 maio 2013. 
Relações intergovernamentais na educação...

BRASIL. Decreto n. 6.170, de 25 de julho de 2007. Dispõe sobre as normas relativas às transferências de recursos da União mediante convênios e contratos de repasse, e dá outras providências. Disponível em: <http://www.planalto.gov.br/ccivil_03/_ato20072010/2007/decreto/d6170.htm>. Acesso em: 7 maio 2013.

BRASIL. Parecer CNE/CEB n. 9, de 30 de agosto de 2011. Análise de proposta de fortalecimento e implementação do regime de colaboração mediante arranjos de desenvolvimento da educação. Disponível em: <http://portal.mec.gov.br/index.php? option=com_content\&id=16368\&Itemid=866>. Acesso em: 8 maio 2013.

CONSÓRCIO INTERMUNICIAPAL DAS BACIAS DOS RIOS PIRACICABA, CAPIVARI E JUNDIAÍ. Disponível em <http://www.agua.org.br/>. Acesso em: 22 ago. 2013.

CONSÓRCIO INTERMUNICIPAL DO GRANDE ABC. Disponível em: <http://www. consorcioabc.sp.gov.br/>. Acesso em: 22 ago. 2013.

CRUZ, M.C.M.T.; ARAÚJO, F.F.; BATISTA, S. Consórcios numa perspectiva histórico-institucional. In: Cadernos Adenauer, Rio de Janeiro, v. 12, n.4, p. 11-124, 2011.

CURY, C.R.J. A questão federativa e a educação escolar. In: OLIVEIRA, R.P.; SANTANA, W. (Org.). Educação e federalismo no Brasil: combater as desigualdades, garantir a diversidade. Brasília: Unesco, 2010.

FIRKOWSKI, O.L.C.F. Metrópoles e regiões metropolitanas no Brasil: conciliação ou divórcio? In: FURTADO, B.; KRAUSE, C.; FRANÇA, C.B.F. (Ed.). Território metropolitano, políticas municipais: por soluções conjuntas de problemas urbanos no âmbito metropolitano. Brasília, DF: IPEA, 2013.

IBGE. Perfil dos municípios brasileiros, 2011. Disponível em: <http://www.ibge.gov. br/home/estatistica/economia/perfilmunic/2011/defaulttab_pdf.shtm>. Acesso em: 22 jul. 2013.

LUCE, M.B.; FARENZENA, N. O regime de colaboração intergovernamental. In: GRACIANO, M. (Org.). O Plano de Desenvolvimento da Educação (PDE). São Paulo: Ação Educativa, 2007. p. 9-13. v. 4.

OLIVEIRA, C. A municipalização do ensino brasileiro. In: OLIVEIRA, C. et al. (Org.). Municipalização do ensino no Brasil. Belo Horizonte: Autêntica, 1999.

OLIVEIRA, C. et al. Conselhos Municipais de Educação: um estudo na Região Metropolitana de Campinas. Campinas: Alínea, 2006.

OLIVEIRA, D. Das políticas de governo às políticas de governo à política de estado: reflexões sobre a atual agenda educacional brasileira. Educação E Sociedade, Campinas, v. 32, n. 115, p. 323-337, abr./jun. 2011. 
NAGLE, J. Educação e sociedade na Primeira República. São Paulo: EPU, 1974.

ROSSINHOLI, M. Política de financiamento da educação básica no Brasil: do Fundef ao Fundeb. Brasília, DF: Líber Livro, 2010.

SUCUPIRA, N. O Ato Adicional de 1834 e a descentralização da educação. In, FÁVERO, O. (Org.). A educação nas constituintes brasileiras 1823-1988. Campinas: Autores Associados, 1996.

Recebido em 30 de setembro de 2013.

Aprovado em 21 de novembro de 2013. 
